International Journal of Engineering \&Technology, $7(3.12)(2018)$ 876-879
International Journal of Engineering \& Technology
SPC
Website: www.sciencepubco.com/index.php/IJET
Research paper

\title{
Intelligent Lighting System and Garbage Monitoring System
}

\author{
U.M.Prakash ${ }^{1}$, Priyanshu Madan², K.R. GokulAnand ${ }^{3}$, S.Prabhakaran ${ }^{4}$ \\ Department of Computer Science and Engineering, SRM Institute of Science and Technology

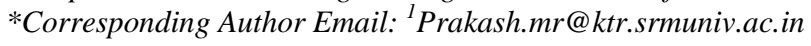

\begin{abstract}
This paper aims at designing a system that focusses on two major societal issues in India i.e. improper garbage management and loss of energy from existing street lighting systems. We designed an intelligent lighting system Using embedded systems and machine learning algorithm we predict the environmental lighting conditions and accordingly change the behavior of the street lights. The present street lighting systems use timer or manual interaction to turn on and off the lights. But these methods are not energy efficient. In our model, we used Light Dependent Resistor LDR and algorithm to eliminate those drawbacks. In Garbage monitoring system, alerting the concerned authorities about the level of garbage collected was the most important aspect. In this system, an Ultrasonic sensor along with machine learning algorithm was used to solve the above situation.
\end{abstract}

\section{Introduction}

\section{A. Intelligent Lighting System}

Street lighting system is a concern for both governmental and public authorities in India. A large amount of energy is consumed only to power the street lamps and most of this energy is wasted due to being unnecessarily being turned on when not needed. Manual turning off may prevent energy wastage to some extent but these require human intervention and most of the time remained turned when not addressed. Different environmental conditions also play a critical role in the behavior of the streetlamps. If the surrounding light is enough to see around then the street lamps are not required. Hence a dynamic solution is required which can adapt to the surrounding light and reduce the energy consumption to a large extent.

\section{B. Garbage Monitoring System}

Waste management system is the biggest problem that needs to be looked upon. According to recent study, India generates 62 million tons of municipal solid waste per annum. Managing this amount of waste has its own problems. Many diseases are caused due to unattended waste and has diverse effect on landfills and the fertility of the soil decreases. We believe that our proposed system will not only alert the concerned authorities but also determine and recommend their work schedule. This system will bring us towards a cleaner world.

\section{Related Work}

\section{A. Intelligent Lighting System}

Traditional lighting systems use timer [1] or manual interaction to turn on and off the lights. But these methods are not energy efficient. The sunlight intensity changes with change in season, during summer the days are longer and during winter the days are shorter. In this case the timer is not very effective as human interaction is required to change the time of the timer.[2] LDRs are also used but they are only used as a switch, it is not dynamic. They don't use machine learning algorithms to predict the lighting conditions. In earlier systems no algorithms were used, they were simply an application but in this model, we have added machine learning algorithms.

\section{B. Garbage Monitoring System}

The way that we follow presently[3] for manually monitoring the wastes is very complex process and so much of human effort, time and money goes into it which is not compatible with the presentday technologies. [2] Present Smart waste disposal systems only provide the level of garbage level and alert only the municipal. In the pre-existing system either the filled dustbin location is sent to municipal corporation or indication of filled dustbin is given but this model on the basis of machine learning algorithm will predict the arrival of municipal corporation to collect the garbage. Improper management of waste causes many major problems such as environmental pollution, airborne diseases and has adverse effects on the living conditions of human beings. In order to overcome all these problems, we are proposing the idea of smart waste management system that involves less human interaction in order to maintain a clean environment.

\section{Proposed System}

\section{A. Intelligent Lighting System}

It is a simple and powerful concept, it uses LDR to measure the intensity of sunlight and use this reading to change the behavior of the street light system automatically. The light is switched ON automatically when the sun goes down (example in evening after Sunset) and the light is automatically switched OFF when light falls on it. For example, in morning, the brightness of light may vary depending upon the peak hours of traffic, season, weather, time of day, etc. The data collected through LDR will be intensity of sunlight during different time of the day. This data will 
dynamically change the intensity in real time. Multiple Linear regression algorithm will be applied on the data to predict the lighting conditions beforehand. The data will be stored in the form of .CSV file.

In multiple linear Regression algorithm, there is a relationship between a scaler dependent variable or target variable which is (Charge value) here and many independent variable, here it is (TIME) and (DAY). Charge value is the amount of charge stored in the capacitor when light falls on the LDR (Light Dependent Resistor). In this model, we will predict the intensity of light of the bulb on the lamp post at a particular time of a particular day. First, the data will be collected for a month or two. Based on that data multiple linear equation will be constructed between the target variable and the independent variables that is between the values of time, day and the charge value. Here intensity or charge value is dependent on day and time of the day.

An equation of the following form will be created:

$\mathrm{Y}=[(\mathrm{M} 1) *(\mathrm{x} 1)]+[(\mathrm{M} 2) *(\mathrm{x} 2)]+\mathrm{C}$

$\mathrm{X} 1 \rightarrow$ Time

$\mathrm{X} 2 \rightarrow$ Day

Once this equation is created, the prediction of the value of charge by using the value of time and day will be done.

\begin{tabular}{|r|l|r|}
\hline 13 & DAY DATE TIME & CHARGE VALUE \\
\hline 14 & [ Sat Oct 14 16:30:46 2017 & 100 \\
\hline 15 & [ Sat Oct 14 16:30:47 2017 & 100 \\
\hline 16 & [ Sat Oct 14 16:30:48 2017 & 100 \\
\hline 17 & [ Sat Oct 14 16:30:49 2017 & 100 \\
\hline 18 & [ Sat Oct 14 16:30:50 2017 & 100 \\
\hline 19 & [ Sat Oct 14 16:30:51 2017 & 100 \\
\hline 20 & [ Sat Oct 14 16:30:52 2017 & 100 \\
\hline 21 & [ Sat Oct 14 16:30:53 2017 & 100 \\
\hline 22 & [ Sat Oct 14 16:30:53 2017 & 89 \\
\hline 23 & [ Sat Oct 14 16:30:54 2017 & 100 \\
\hline 24 & [ Sat Oct 14 16:30:55 2017 & 100 \\
\hline 25 & [ Sat Oct 14 16:30:56 2017 & 54 \\
\hline 26 & [ Sat Oct 14 16:30:56 2017 & 20 \\
\hline 27 & [ Sat Oct 14 16:30:56 2017 & 18 \\
\hline 28 & [ Sat Oct 14 16:30:56 2017 & 15 \\
\hline 29 & [ Sat Oct 14 16:30:57 2017 & 15 \\
\hline 30 & [ Sat Oct 14 16:30:57 2017 & 15 \\
\hline 31 & [ Sat Oct 14 16:30:57 2017 & 15 \\
\hline 32 & [ Sat Oct 14 16:30:57 2017 & 50 \\
\hline 33 & [ Sat Oct 14 16:30:58 2017 & 100 \\
\hline 34 & [ Sat Oct 14 16:30:59 2017 & 100 \\
\hline 35 & [ Sat Oct 14 16:31:00 2017 & 100 \\
\hline 36 & [ Sat Oct 14 16:31:01 2017 & 100 \\
\hline 37 & [ Sat Oct 14 16:31:02 2017 & 100 \\
\hline
\end{tabular}

Fig. 1: Real time data of light intensity detected

\section{B. Garbage Monitoring System}

It uses Ultrasonic sensor which is fixed at the top of the bin. Ultrasonic sensor uses the concept of reflection of sound to measure the distance of an object. It will measure the level of garbage in the bin. The level of garbage will then be displayed on top of the bin using LEDs. The data thus collected will be sent to the server through GSM module. Machine learning algorithm (Linear regression) will analyze the data and provide the peak hours of garbage collected. This will give the estimate time of the day when the garbage needs to be collected. Each bin will have a unique ID and GPS coordinates will give the location of that pin to the concerned authorities. The data will be stored in the form of .CSV file and then Linear Regression machine algorithm will be applied on making prediction of time when dustbin will get fill on a particular day.

\begin{tabular}{|l|r|}
\hline DATE AND TIME & Garbage (CM) \\
\hline [ Sat Oct 14 16:30:47 2017 & 10 \\
\hline [ Sat Oct 14 16:30:48 2017 & 10 \\
\hline [ Sat Oct 14 16:30:49 2017 & 10 \\
\hline [ Sat Oct 14 16:30:50 2017 & 10 \\
\hline [ Sat Oct 14 16:30:51 2017 & 10 \\
\hline [ Sat Oct 14 16:30:52 2017 & 10 \\
\hline [ Sat Oct 14 16:30:53 2017 & 6 \\
\hline [ Sat Oct 14 16:30:53 2017 & 6 \\
\hline [ Sat Oct 14 16:30:54 2017 & 6 \\
\hline [ Sat Oct 14 16:30:55 2017 & 5 \\
\hline [ Sat Oct 14 16:30:56 2017 & 4 \\
\hline [ Sat Oct 14 16:30:56 2017 & 4 \\
\hline [ Sat Oct 14 16:30:56 2017 & 4 \\
\hline [ Sat Oct 14 16:30:56 2017 & 3 \\
\hline [ Sat Oct 14 16:30:57 2017 & 2 \\
\hline [ Sat Oct 14 16:30:57 2017 & 0 \\
\hline [ Sat Oct 14 16:30:57 2017 & 0 \\
\hline [ Sat Oct 14 16:30:57 2017 & 0 \\
\hline
\end{tabular}

Fig. 2: Real time data of amount of garbage collected

In linear Regression algorithm, there is relationship between a scaler dependent variable (Distance) and one independent variable (TIME). Distance is the amount of Garbage collected in the bin. Smaller the distance, more is the amount of garbage. In this model, we will predict the amount of garbage collected at a particular time of day. First, the data will be collected for a month or two. Based on that data a liner model will be constructed between the values of time and distance.

The equation will be of the form: $\mathrm{Y}=\mathrm{M} * \mathrm{x}+\mathrm{C}$.

$\mathrm{Y} \rightarrow$ distance

$X \rightarrow$ time of the day

Once this model is created, we can predict the value of distance by using the value of time. This will further be used in the application part of the module. When $50 \%$ of the total dustbins present in an institution gets filled then a message will go to the concerned authority to pick up the garbage.

\section{Architecture}

\section{A. Intelligent Lighting System}

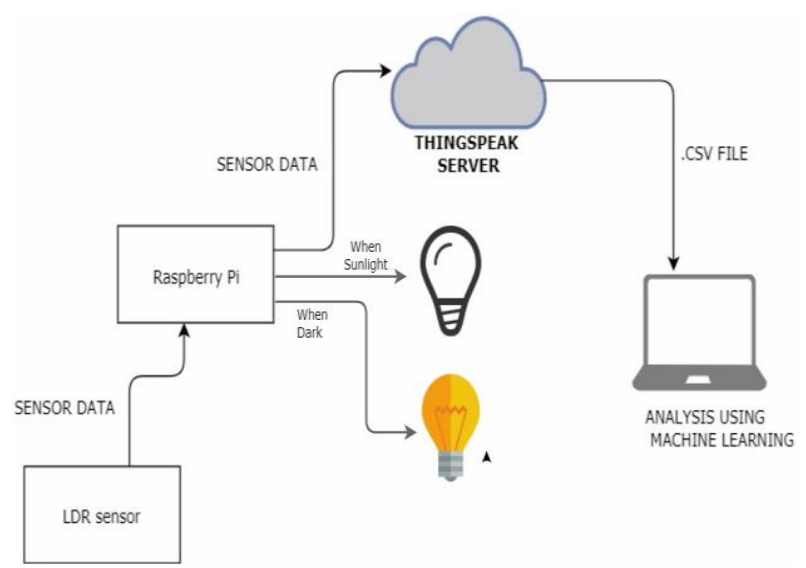

Fig. 3: Architecture of Intelligent Lighting System 
This figure explains the working architecture of the intelligent lighting system. Light Dependent Resistor (LDR)is a light variable resistor. The resistance of the LDR decreases with increase in the intensity of light.

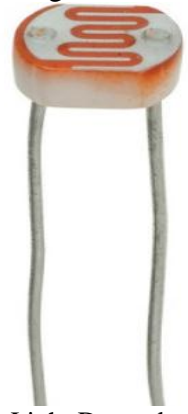

Fig. 4: Light Dependent Resistor

Here, the LDR senses the intensity of the surrounding light and sends the data to Raspberry-pi in the form of Resistant Charge. Resistant Charge is the amount of charge stored in capacitor when light falls on the LDR. It is inversely proportional to the resistivity of the cell which is in-turn inversely proportional to the amount of light falling on it. The sensor data will be stored in a form of .csv file format. The file will contain the charge data along with the date and time. The reason it is stored with the time and date because it will help us predict the lighting conditions at every second, month and season of the year. For example, in winter season the amount of sunlight is very less and the days are shorter with respect to the lighting conditions in other season, hence it makes sense to increase the intensity of light in that season dynamically. If there are exceptions in the lighting conditions the real-time data will be analyzed and the street lighting conditions will change accordingly.As the Raspberry-pi has an onboard WiFi module the file with the sensor data will be sent to the host server through Wi-Fi. Multiple Linear Regression Algorithm will be applied on the data. After applying this algorithm on data collected over a week, predictions can be made about the intensity of sunlight throughout the day. The Predictions will be sent back to the Thinkspeak. Thinkspeak is an online client that collects, analyze and triggers an action. So, whenever there is an abnormal change in the lighting conditions of the surrounding a trigger is initiated to manipulate the behavior of the streetlamps.

\section{B. Garbage Monitoring System}

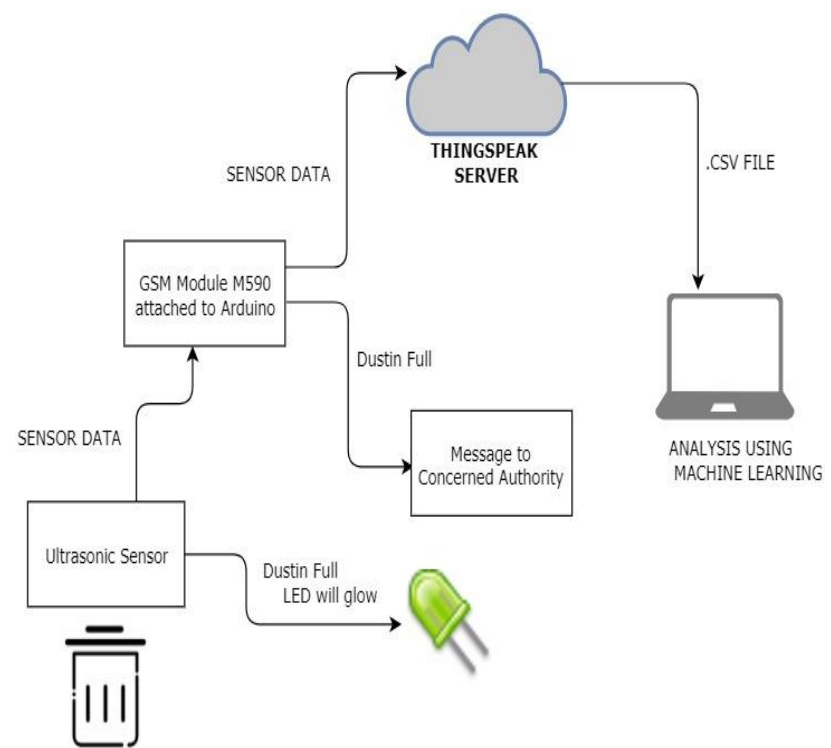

Fig. 5: Architecture of Garbage Monitoring System

Fig explains the working architecture of the garbage monitoring system. It comprises of an ultrasonic sensor HC-SR04 connected to an Arduino that senses the level of garbage in the bins and sends the data to the host server through a GSM M590 module.

Since Arduino does not have an onboard communication protocol to transfer data, a GSM module was required to send the data across platforms.

A series of LED lights are used to notify the pedestrians the amount of garbage collected or amount of space available to throw the garbage so that they don't have to approach the bin to know the level of garbage in it.

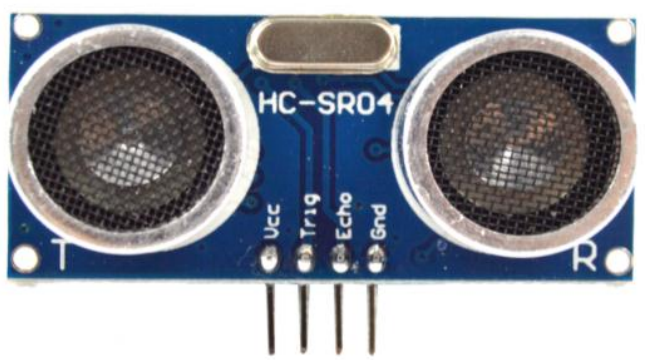

Fig. 6: HC-SR04 Ultrasonic sensor

The sensor data is stored in .csv file format which contain the distance of the garbage from the brim of the bin along with the date and time. The reason it is stored with date and time is because it will help to predict the busiest hour of the day when the amount of garbage collected in bin is large. Also help to predict the busiest days of the week when the amount of garbage is very high. For example, weekdays are the busiest days of the week as these are the working days. So, the concerned authorities need to be alert on these days where as the weekends are not busy and hence the amount of garbage collected will be less. This will save human resources as well as the cost and fuel to collect the garbage.Multiple Linear Regression Algorithm will be applied on the data.

After applying this algorithm on data collected over a week, predictions can be made about the garbage collected throughout the day as well as throughout the week. The Predictions will be sent back to the Thinkspeak. Thinkspeak is an online client that collects, analyze and triggers an action. So, whenever a garbage bin is full a trigger is initiated and an alert is sent to the municipal corporation to collect the garbage.

\section{Circuit Layout}

\section{A. Intelligent Lighting System}

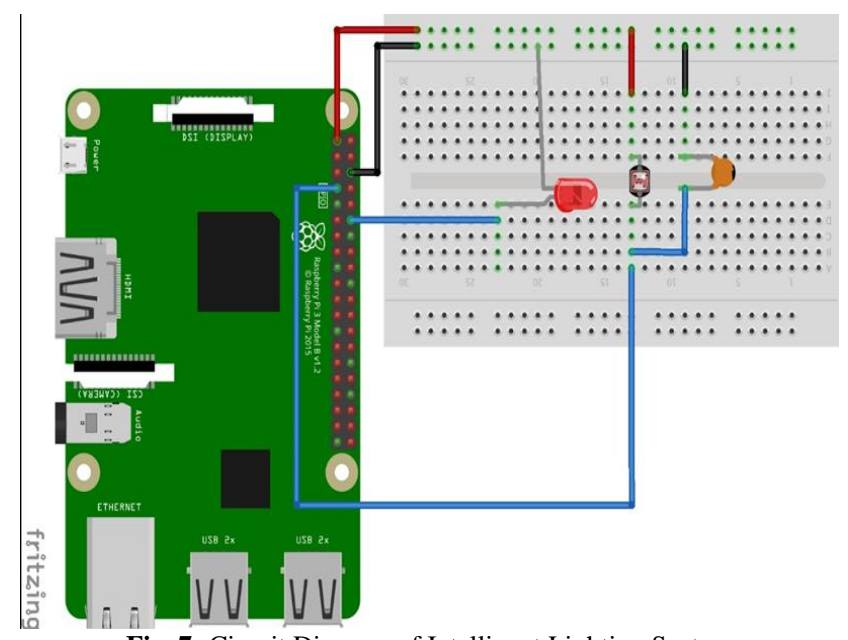

Fig. 7: Circuit Diagram of Intelligent Lighting System

The circuit of Intelligent lighting system consists of a breadboard, Light Dependent Resistor LDR, Capacitor, Raspberry-Pi. The Raspberry-pi consists of 40 GPIO ports out of which of 4 power pins and 7 ground pins. The rest of the pins are analog and digital 
pins that transmit and receive data. The LDR is connected to an 100uf capacitor. The charge stored in the capacitor is what is being

transmitted to the Raspberry-Pi. After analysis, the signals are transmitted from the raspberry-pi to the LED panels of the street lamp to manipulate the brightness of the lamps. Raspberry-pi has onboard Wi-Fi chip, hence external communication protocols are not required. In this system 2 GPIO ports and 2 power pins are used.

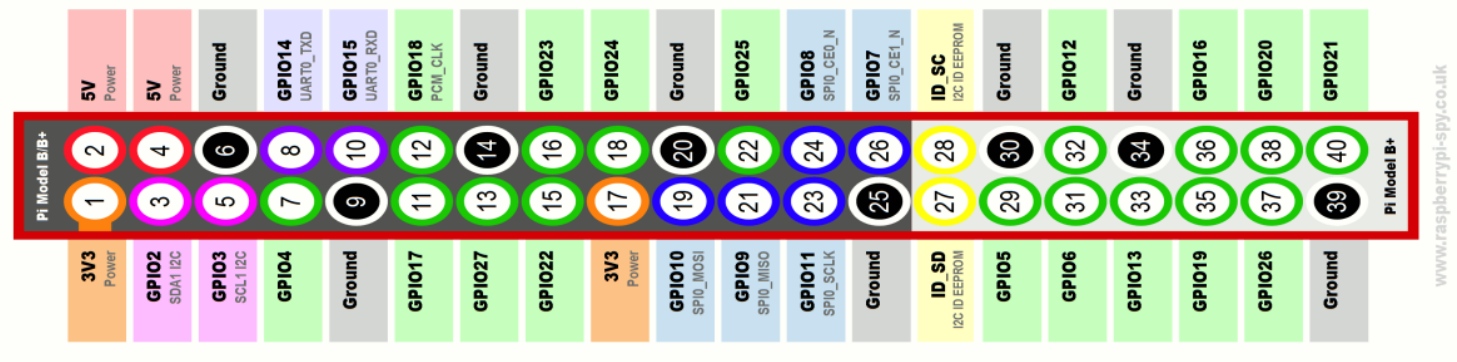

Fig. 8: Raspberry-Pi pin configuration

\section{B. Garbage Monitoring System}

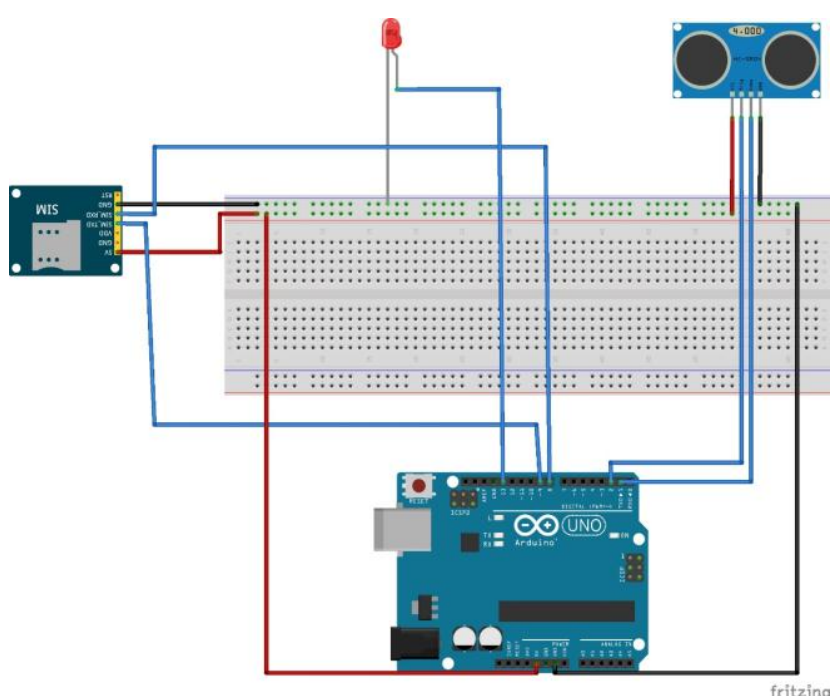

Fig. 9: Circuit Diagram of Garbage Monitoring System

The circuit diagram of the garbage monitoring system consists of an Arduino Uno board, HC-SR04 ultrasonic sensor, LEDs and GSM module. HC-SR04 uses 2 GPIO Ports and 2 Power Pins. The Ultrasonic sensor has one transmitter pin which initiates the transmission of sound waves and one echo pin which receives the sound waves after reflection. The time duration between transmission and receiving of sound waves determine the distance of the obstacle.

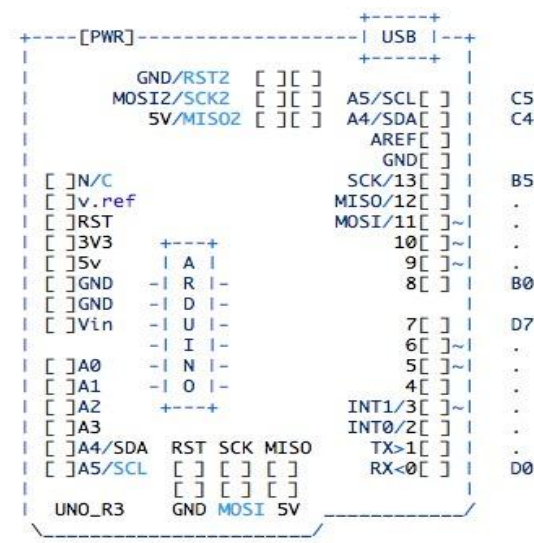

Fig. 10: Arduino Uno pin configuration

\section{References}

[1] P. A. Ambresh, M. Ashwini, Rickson Wilson Rodrigues, Vikesh And G. M. Puspanjali "Design Of Smart Automatic Street Light System”, NCRIET-2015 \& Indian J.Sci.Res. 12(1):028-032, 2015

[2] SharathPatilG.S ,Rudresh S.M , Kallendrachari.K ,M Kiran Kumar , Vani H.V "Design and Implementation of Automatic Street Light Control Using Sensors and Solar Panel" Int. Journal of Engineering Research and Applications ISSN : 2248-9622.

[3] A. Ahsan, M. Alamgir, M. M. El-Sergany, S. Shams, M. K. Rowshon, and N. N. Nik Daud "Assessment of Municipal Solid Waste Management System in a Developing Country", Chinese Journal of Engineering Volume 2014, Article ID 561935

[4] Mrs.D.Anuradha , A.Vanitha ,S.PadmaPriya ,S.Maheshwari , "Waste Management System Using Iot", International Journal of Computer Science Trends and Technology (IJCST) - Volume 5 Issue 2, Mar - Apr 2017

[5] RFID and Integrated Technologies for Solid Waste Bin Monitoring System . Proceedings of the World Congress on Engineering 2010, June 30 - July 2, 2010, Vol I

[6] Islam, M.S. Arebey, M. ;Hannan, M.A. ; Basri, H,’Overview for solid waste bin monitoring and collection system" Innovation Management and Technology Research (ICIMTR), 2012 International Conference, Malacca, 258 - 262.

[7] B. Vinothkumar, K. Sivaranjani, M. Sugunadevi, V. Vijayakumar, "IOT Based Garbage Management System", International Journal of Science and Research (IJSR), vol. 6, pp. 99-101, March 2017.

[8] M. SandeepChaware, S. Dighe, A. Joshi, N. Bajare, R. Korke, "Smart Garbage Monitoring System Using Internet of Things(IoT)", International Journal of Innovative Research In Electrical Electronics Instrumentation and Control Engineering, vol. 5, no. 1, pp. 74-77, January 2017

[9] S. Shukla, N. Shukla, "Smart Waste Collection System based on IoT: A survey", International Journal of Computer Applications, vol. 162, no. 3, pp. 42-44, March 2017.

[10] Shinjini Ray, SayanTapadar, Suhrid Krishna Chatterjee, Robin Karlose, SudiptaSaha, HimadriNathSaha, "Optimizing routine collection efficiency in IoT based garbage collection monitoring systems", Computing and Communication Workshop and Conference (CCWC) 2018 IEEE 8th Annual, pp. 84-90, 2018. 